\title{
Exploration of Self-Consciousness through Self and Other Recognition in the Mirror:Towards New Perspectives in Schizophrenia
}

\author{
Tom Motillon ${ }^{1, \dagger}$, Gaelle Keromnes ${ }^{1}$, Sylvie Tordjman ${ }^{1,2}$
}

\begin{abstract}
Self-experience impairments have been described since many years as part of core features of schizophrenia, but are currently neglected in research and clinical practice. First, a literature review on self-consciousness is developed in this article with regard to definitions (including the concepts of self and self-consciousness) and different approaches (especially cognitive, developmental and neurobiological approaches). Self-consciousness can be divided into three levels: minimal-self with implicit pre-reflexive consciousness, reflexive-self with explicit reflexive consciousness (consciousness of a permanent self as an invariant over time through multiple experiences and actions), and social-self (style, habits, and historical narrativity) with explicit self-consciousness. These levels appear progressively in the child from bodily perception (pre-reflexive consciousness) to identification of the self in the mirror at approximatively two-years old (reflexive consciousness) and appearance of mental representations later (self-consciousness). Second, self-consciousness impairments observed in schizophrenia are described in this article and discussed in light of the literature presented. Converging evidence suggests that exploring self-disorders in schizophrenia could help clinicians to understand daily-life patients difficulties and might be of interest for developing a therapeutic alliance. Finally, this critical literature review opens new perspectives to understand better disorders of the self and social interaction impairments in schizophrenia, and to propose a therapeutic use of the mirror based on cognitive remediation helping individuals with schizophrenia to improve self-other differentiation.
\end{abstract}

Keywords

Schizophrenia; Consciousness; Awareness; Body-self; Mirro; Minimal self; Perception

\section{Introduction}

Self-consciousness is a multidimensional concept that involves as much consciousness of one's own body and image as self-recognition with consciousness of one's own identity. Selfconsciousness impairments have been described in schizophrenia based particularly on difficulties in self-other differentiation.

In this article, a literature review on selfconsciousness is first developed with regard to definitions (including the concepts of self and self-consciousness) and different approaches (especially cognitive, developmental and neurobiological approaches). Then, self-

'Pôle Hospitalo-Universitaire de Psychiatrie de l'Enfant et de l'Adolescent, Université de Rennes 1 and Centre Hospitalier Guillaume Régnier, 154 rue de Châtillon, 35200 Rennes, France

²Laboratoire Psychologie de la Perception, CNRS UMR 8158, Paris, France

*These authors contributed equally to this work

${ }^{\dagger}$ Author for correspondence: Tom Motillon, Pôle Hospitalo-Universitaire de Psychiatrie de l'Enfant et de l'Adolescent, Université de Rennes 1 and Centre Hospitalier Guillaume Régnier, 154 rue de Châtillon, 35200 Rennes, France, Tel: +33647003289; Fax: +3329932 46 98; email: motillon.tom@gmail.com 
consciousness impairments observed in schizophrenia are described and discussed in light of the literature presented. Finally, this critical literature review opens perspectives on a new methodology for the objective exploration of perturbations of self-consciousness in schizophrenic disorders based on the study of self and other recognition in the mirror.

\section{- Concepts of Self-Consciousness: Definitions and Cognitive Contributions}

Definitions of self (self) and self-consciousness (some authors use the terms of self-consciousness or self-awareness) are variable across fields of study, and different authors. Therefore it is necessary to define these concepts in order to situate better our object of study. There are several levels of study of the self [1]:

- Philosophy distinguishes phenomenology and philosophy of mind, both involved in the sense of self. Phenomenology describes the essence, content and sensations associated with a mental state. Philosophy of mind is centered on logical thinking and systematization of our knowledge of the mind.

- Social sciences study how people perceive themselves, their different roles in society and how these factors interact with each other.

- Cognitive science constructs models of functioning of the mind and the development of the self from healthy subjects and patients.

- Neuroscience studies the links between mental phenomena and brain states and their structures involved in self representations through imaging and electrophysiology techniques.

- Clinical sciences describe psychopathology and the different mental disorders where self- alterations have been observed.

Damasio defines consciousness as a state of mind characterized by « knowledge of our existence and that which surrounds us "[2]. Kihlstrom defines the Self as a personal mental representation of one's own personality or identity, formed from lived experiences, thoughts encoded in memory; it is constituted and structured by a set of patterns, prototypes, images, and goals, each defined by descriptive information about the characteristics, roles, behaviors, rules, or inference procedures [3]. According to Jaspers, the different dimensions of the self include the activity and the action that allow reaching consciousness of one's own existence, the self as a whole and a unity, identity in the course of time (temporal permanence of the self), and the self / non-self-differentiation. Self-alterations may occur at one of its four previous levels [4]. Scharfetter has developed the definitions of Jaspers by adding the notions of vitality and continuity [5]. Schneider (1959) talked about ego bundaires which refers to the limits of the ego. Merleau-Ponty insisted on the importance of the "lived body " in self-consciousness. The importance of awareness of bodily self was described by Blanke [6] for which the awareness of bodily self is based in 3D space : the identification of oneself (experience of living in one's body), the localization of oneself in space, and perspective in the first person (experience from which one sees the world).

These different definitions throughout time allow us to have a more precise view on selfconsciousness. The self has been then divided in three dimensions depending on the level of complexity [7]:

- The most basic level is the minimal self (prereflective self or self-implied). It refers to living as an immediate subject of experience. Subject and experience are one. This is the ultimate basis of the experience.

The reflexive self-concerns an explicit level. It is about the consciousness of a "I " as the invariant pole of the individual through multiple experiences and actions.

- The most complex level is the narrative self where the notion of person (social self) appears. It is a coherent and continuous self-representation over time, based on autobiographical memory. The individual perceives him/herself as an object. At this level, self-esteem and self-image in psychology are relevant.

\section{Development of Self-Consciousness}

Self-consciousness is a skill that develops gradually in human beings. From birth, the infant is able to distinguish certain tactile stimuli coming from one, from those derived from someone else suggesting the existence of a bodily self. He will thus have more important reactions when touching the cheek when it comes from someone else [8]. Thus, in humans, there would be an early ability to distinguish between tactile 
stimuli coming from one and from others. Touch is, moreover, the first sense which develops in the fetus [9].

According to Freudian theory, libido (psychic energy characterized by its source, object and purpose) [10] would initially be anonymous and not directed. Progressively this would be addressed more specifically according to the needs and desires of the child. Piaget evoked an initial period of autism and then a period of egocentrism [11]. In any case, it was hypohesized to begin with indifferentiation between "self " and " outside " with a concept based on the absence of delimitation of endogenous and exogenous sensori-motor actions. The infant could then only associate the reactions of others with his/her own emotional behavior (for example, breastfeeding after expressing anger).

For Winnicott, the link to the mother very soon plays the role of " first mirror " allowing the infant to experience a first identity base [12]. Primary narcissism would be the libidinal investment of the bodily self in which mental representations of the self are confused with the object. Secondary narcissism would lie in the libidinal investment of self-representation. The individual then acquires autonomy from the object, a sense of self continuity. The possibility for the child to recognize him- or herself through the image in the mirror represents this transition from primary narcissism to secondary narcissism. The individual becomes capable of perceiving oneself as an object, of investing selfrepresentation, and therefore of differentiating subject and object. This marks the delimitation between outside and an internal space proper to the child. In order for the person to succeed in unifying his/her self in space, the person must place his/her exteroceptive ego in such a way that perception becomes essentially unrealizable for him/ her. According to Wallon, as soon as he/she sees his/her own image, he/she ceases to coincide in space with his/her own body and must see it as being without reality [13]. The child must apprehend him/ herself as an object gradually in order to develop self-consciousness. Wallon evoked this in another way by saying that it is by the consciousness of the other that the notion of one's own body is developed. It has been stated that disorders of self-consciousness in children and adolescents could be due to a lack of passage from primary narcissism to secondary narcissism with the coexistence of the two modes of narcissistic relation to the object [14].
Recognition of the self-image would be a competence found in human beings but also in other species. Studies in the chimpanzee, bonobos and orangutans have shown their ability to recognize themselves in front of a mirror in these species [15]. This skill could go back to between 14 and 18 million years [16]. In the chimpanzee, this skill emerges around 5-7 years [6].

Zazzo [17] described five stages in the child's reactions to the mirror:

- Lack of reaction;

- Looking at the image of another but not his/ her own image (3 months);

- Turning away from the image of the person and beginning to take an interest in his/her own image (8 months);

- $\quad$ Mainly interested in his/her image (1 year);

- Presenting reactions of disarray and then explicit recognition (2 years).

According to Zazzo, the consciousness of the other is acquired in babies at the age of 8 months and self-consciousness at the age of 2 years.

More recently, several authors [2,18-20] have proposed different models conceptualizing the self with developmental levels of consciousness described in Table 1. Among these authors, Rochat distinguished five levels of selfconsciousness in children aged 0 to 5 [18]:

- Confusion (level 0): the individual is not aware of the reflection caused by the mirror. It is the period when the image reflected in the mirror is analyzed as part of the environment (e.g., in birds or certain animals such as cats or dogs).

- Differentiation: early realization that the mirror is not like the rest of the environment. It is the first level of self-consciousness with the discovery and experience that body movements are coordinated with what is reflected by the mirror. This skill would be observable in infant soon after birth.

- Situation: proto-narcissistic stage corresponding to the period when the individual makes the link between his/her physical sensations through intermodal sensory perception and movements reflected in the mirror. The individual is aware that the mirror is external to him/her. This competence is present in 2-months old 


\begin{tabular}{|c|c|c|}
\hline & Consciousness & \\
\hline \multirow{8}{*}{$\begin{array}{l}\text { Levels of } \\
\text { consciousness* }\end{array}$} & Pre-reflexive consciousness (implicit) & Early appearance, relies on bodily perception \\
\hline & - Level 1: Differentiation & - Relies on the experience of own bodily movements \\
\hline & - Level 2: Situation & - Relies on intermodal sensory perception of the own body \\
\hline & Reflexive consciousness (explicit) & The self is expressed explicitly \\
\hline & - Level 3: Identification & -Identification of the self in the mirror \\
\hline & - Level 4: Permanence & - Identification of a permanent self (invariant over time), in pictures and movies \\
\hline & Self-consciousness (explicit) & Later appearance, relies on mental representations \\
\hline & • Level 5: "Meta" self-awareness & - Notably, representations of how the child is perceived by others \\
\hline \multirow{4}{*}{$\begin{array}{l}\text { Type of } \\
\text { consciousness }\end{array}$} & Agency & Consciousness of volition and ownership \\
\hline & Distinctiveness & Consciousness of uniqueness \\
\hline & Personal Continuity & Consciousness of continuity through time \\
\hline & Reflection & Consciousness of consciousness \\
\hline \multirow{4}{*}{$\begin{array}{l}\text { Contents of } \\
\text { consciousness }\end{array}$} & Physical & Physical features \\
\hline & Active & Action skills \\
\hline & Psychological & Traits and values \\
\hline & Social/relational/collective & Social role and membership, reputation, relationship to others \\
\hline \multirow{4}{*}{$\begin{array}{l}\text { Alterations of self- } \\
\text { consclousness }\end{array}$} & Presence & $\begin{array}{l}\text { The sense of personal experience becomes affected } \\
\text { Striking tendency to experience one' s body predominantly as an object: } \\
\text { an increasing experiential distance between subjectivity and corporeality } \\
\text { ("disembodiment"). }\end{array}$ \\
\hline & Stream of Consciouness & $\begin{array}{l}\text { Mental contents become quasi-autonomous ("automatic" thoughts), without } \\
\text { ipseity and with a rupture of the stream of thoughts (thoughts may appear as if } \\
\text { from nowhere) }\end{array}$ \\
\hline & Self-demarcation & Inferential reflection arises as a consequence of a deficient sense of myness \\
\hline & Solipsism and existential reorientation & $\begin{array}{l}\text { To be excessively preoccupied with philosophical, supernatural, or metaphysical } \\
\text { themes }\end{array}$ \\
\hline
\end{tabular}

infants. Until the age of 12 months, the child reacts by smiles and vocalizations to the mirror as if he/she was in the presence of another child.

- Identification: developmental period when the child becomes able to recognize him/ herself in the mirror, saying " $\mathrm{I}$ ", to remove a post-it from his/her forehead for example. This skill is present in children from 2 years of age [21,22].

- Permanence: ability to recognize beyond the moment, beyond the here and now of the experience of the mirror. The individual becomes able to identify him/herself on previous photos and videos. Appearance of a permanent self (spatio-temporal permanence. This competence is observable in 3-year-old children. The infant acquires a body schema by experiments on his/her body and the comparison between him/ herself and others [23].
- Self-consiousness or meta self-consciousness: ability to see not only oneself as the first person but also as a third person, to be aware of how one can be perceived by others. It refers to the capacity to represent possible representations that others have of us. This skill is present in children around 4-5 years.

Thus, the development of the recognition of one's self-image is contemporaneous with the development of self-consciousness with the emergence of prosocial behaviors, the use of " "I" " and autobiographical memory [24] (Table 1).

\section{Neurobiological Approach}

\section{- The system of mirror neurons}

Mirror neurons were described in 1990 by Giacomo Rizzolati [25]. It is a group of motor neurons that activate both when we perform a given action but also when we see someone else performing the same action and when we think 
of its accomplishment. Their description was made from observations in monkeys who could perform an action immediately after having seen it in one of their peers, mirroring the other. The brain regions involved in this " mirror " reaction are the premotor frontal cortex, the upper temporal sulculum and some parietal areas. No activation of the visual areas was found [26]. In the great ape, the brain area F5 (Broca's area in man) could play a role in the mirror neuron system showing the implication of language and ability to communicate with the other. More generally, the involvement of mirror neurons in social cognition and empathy ("neurons") was mentioned. Currently, the importance of the mirror neuron system is more controversial particularly because of a lack of specificity [27].

\section{- Recognition of self}

The prefrontal cortex, especially the right prefrontal cortex, is involved in many cognitive tasks, including self-recognition. This requires the mobilization of episodic memory, introspection and the theory of mind [28]. The consciousness of a bodily self is based on proprioceptive, vestibular and visual information [29]. In particular, a 2010 meta-analysis [30] highlighted the importance of the medial prefrontal cortex in the process of self-recognition and the recognition of others. From 33 studies on the self they proposed a model where the ventral part of the medial prefrontal cortex would correspond to the localization of the self, whereas the dorsal part would be involved in evaluation and decision making to differentiate the self and others.

Some people have experienced moments outside their own body, with awake observation. These experiences of " out of body " may be due to a dysfunction of the temporo-parietal region with impaired self-consciousness [31]. Integration of sensorimotor and visual signals would be defective, as would visual and vestibular signals under these circumstances. The central role of the temporo-parietal junction in self-consciousness has been confirmed by other studies [32,33]. Thus, lesions of the temporo-parietal region are responsible for asomatognosy, which is the impossibility of recognizing certain parts of one's own body.

\section{- Recognition of one's own image}

Recognition of one's self-image is associated with right hemispheric activity [34,35]. The right temporal lobe, the right limbic system and the fusiform gyrus are activated in recognition tasks of one's own image. Involvement of the left hemisphere has also been shown, which is not in favor of a center for self-image recognition in the right hemisphere. There may be a more complex system of associations of different cerebral neural networks.

Self-image recognition in the mirror is influenced by multimodal perception. Synchronous tactile stimulation when observing another person receiving the same facial touch stimulation leads to a change in the recognition of the selfimage in the direction of confusion with others. This has also been experimented with a tactile stimulus in the back. These experiments go so far as to induce a localization of self-outside of one's own body [36].

\section{- Disturbances in the recognition of self- image}

Experiments of perturbation of selfconsciousness have been described in particular in certain neurological impairments. These include autoscopic hallucinations, heautoscopy (perceiving one's own image in front of oneself), and out of body experiences. These disturbances may have been associated with transient abnormalities of the temporo-parietal junction. This leads to changes in the perception of body self with disturbances in the integration of proprioceptive, tactile and visual information, but also with vestibular disorders [31]. More complex anomalies have been described in schizophrenia.

\section{- The Mirror: socio-historical approach}

The reaction of the individual to the mirror has been studied, as seen previously, through different aproaches (cognitive, developmental, or neurobiological). It could be of interest to replace here the use of the mirror in a sociohistorical context.

\section{- History}

Since prehistoric times, humans have used various materials in order to observe their image (stones or water bowls) [37] . In Greek antiquity, the mirror could have different shapes (convex or concave), and was small $(20 \mathrm{~cm})$. It could serve as a pocket mirror, be held by a slave or fixed to the wall. It was a costly and rare object until the 16th century. Its use developed during the following century in France thanks to technological advances and $70 \%$ of the Parisian households disposed of it at the end of the 17th century. In the countryside, mirrors were rare until the end 
of the 19th century, while in the city they were ubiquitous in public places (restaurants, cafes, theaters, building entrances, etc.).

We can cite the myths of Narcissus and Perseus where the use of reflective power of the mirror is found. In the first myth, the mirror is associated with vanity and causes the loss of Narcissus. In the second myth, it allows the hero to defeat Medusa. Thus the mirror, and more particularly the image of oneself in the mirror, seems to have fascinated mankind at all times.

This fascination can be explained by several reasons. First, it made it possible to see the resemblance between individuals. Then, it has long been associated with sins and represented as an accessory of devils and madmen in literature. Finally, it has an introspective vocation: seeing one's image makes it possible to know one better but could be criticized when associated with the universe of appearances and vices.

\section{- Current use}

In recent years, the use of the mirror has changed. If it is a tool used every day for everyone (toilet, hairdressing, etc.), technological transformations and in particular digital, has disrupted its use. It is now possible to obtain transformed images of one's own face or even to associate several faces together in order to obtain the representation of the face of a virtual being mixing two or more beings. This representation of one's own image is transformed, exchanged, and modeled. It has a communicative, entertainment value. One plays with this image which does not really correspond to who one is and can therefore offer a certain distance.

\section{Self and Schizophrenia}

\section{- Phenomenological approach}

Psychiatric phenomenology has examined the experience of the individual with schizophrenia. Some authors, such as Minkowski, Blankenburg, Tatossian or Kimura, have insisted on the centrality of these alterations in the schizophrenia process. Minkowski introduced the expressions "loss of vital contact with reality" and "loss of the category of feeling" to describe the experience of patients with schizophrenia [38]. From this process the individual will then over-invest the intellectual sphere to compensate for the void felt. It is a form of "rich autism", characterized by morbid rationalism. Subsequently, Binswanger spoke of "missed presence" to describe these perturbations of the patient's experience [39]. This could be viewed as an accentuation of one of the ways of being in the world that characterize human beings. Three ways were described: distortion, mannerism and presumption. Distortion is an approach to the self and others for utilitarian purposes only. Mannerism represents an elevation of the self by another than the self. This refers to an impression of inauthenticity. Presumption is the construction of an ideal which is too high with regard to the patient's experience. The individual engages him/herself in vertiginous projects. The difficulty of being in the world is compensated by an attempt to cling to an appearance without a solid foundation. The individual with schizophrenia may thus adopt one of his/her attitudes excessively in order to compensate for his//her inner vacuum and to adapt. The "loss of natural evidence" characterizes the loss of implicit knowledge of social rules.

Paul Ricoeur distinguished two poles of human identity, Id em and Ipse. Id em designates the permanence of characters that we experience through time, and Ipse designates the permanence of our subjectivity or "promise kept". Narrative identity makes it possible to relate these two concepts. This allows the construction of the subject over time through the events that rhythm his/her life. The individual with schizophrenia would have a disorder of Ipse (selfhood) with a narrative identity disorder expressed through an inability to tell his/her own story.

In typically developing individuals (people without schizophrenia), the different actions produced in everyday life are carried out almost automatically. In individuals with schizophrenia, negative symptoms are associated with hypereflexivity. Gestures and words are systematically analyzed and questioned. One can find in severe cases a perplexity. In less severe cases, this can account for a slowdown, inactivity, listlessness [40].

Minimal self-alterations of the five dimensions are described below and summarized in Table 1 $[7,41]$

- Alteration of the experienced body: The patient loses the ability to perceive his or her own body. He/she contemplates therefore him/herself from outside, in a 3rd person perspective. Perceptions, thoughts and emotions are not experienced as his/her own. This is an experience of "disincarnation of self'. 
- Altered sense of presence: The individual does not own his/her experience. There is a gap between self and the experience of the outside world. Grasping the most obvious meanings is deficient.

- Alteration of stream of consciousness and its mineness: Thoughts can be experienced as coming from nowhere or be localized at a particular place inside the head. There are interruptions in the course of thought; thoughts are experienced as uncontrolled, and their content is meaningless to the person.

- Impaired self-demarcation: The bodily limits of the individual are fragile Thus, experiences of confusion with others, and experiences of threats or major anxiety during physical contact with others are possible. The impression of theft of thought may be seen as an alteration of the limits of the self.

- Sollipsism, existential reorientation: Sollipsism refers to the fact that the individual lives as a single subject of the world; the experience of the patient's centrality, namely that events external to him are addressed to him or her.

Main symptoms of schizophrenia (delusions, hallucinations, influence syndrome) can be seen as alterations in self-consciousness. The distinction between self and others is difficult or even erroneous. There is a loss of natural evidence or a decrease in pre-reflexive self-consciousness. Hallucinations may be an external perception of internal processes. Patients would perceive their own thoughts as thoughts coming from outside and imposing themselves on them through sensory perceptions (visual or auditory) with bodily experience.

\section{- Recognition of self-image}

Few studies have evaluated the recognition of self-image through the mirror in schizophrenia. It has been observed in schizophrenia that patients confrontation with their own image in the mirror can produce some impression that their reflection is distorted, independent of themself or sinister, but also reactions (such as verbalisations, smiles) when facing someone other than self [42]. In addition, an association has been found between the difficulties of recognizing one's own image and the severity of schizotypic disorder or disorganization [43]. Some studies have shown abnormalities in recognition of self-image through the use of photographs [28], but other studies reported preserved recognition of self-image compared to healthy subjects [44].

Furthermore, the Daprati et al. study [45], based on the video presentation of the patient's hand or the experimenter's hand, has shown more pronounced attribution errors in self-recognition for patients with schizophrenia compared to control individuals without schizophrenia. Individuals with schizophrenia made more mistakes than controls by pointing more often to the examiner's hand as their own hand (excess of attribution). Also, when two hands were presented, the patients made more errors by default attribution. These errors were associated with the presence of main productive symptoms of schizophrenia (hallucinations, etc.).

Taken the results of studies together, there are different reactions between individuals with schizophrenia and healthy subjects when recognizing their own image in the mirror as well as abnormalities in agentivity. Moreover, productive symptomatology seems associated with abnormalities of agency and impairments in recognition of self-image [46]. Agentivity is the perception that one is the initiator of his own actions [47]. Several works have shown that body owernship and the sense of agency could both be impaired in patients with schizophrenia $[48,49]$.

\section{- Neurobiological approach}

A dysfunction of the frontal cortex could lead to attribution errors in self-recognition. The mechanism involved might be an inhibition defect in the posterior and inferior areas of the right parietal lobe and primary auditory area [50]. Acoustic-verbal hallucinations may be related to the perception by the patient of his own inner dialogue [50]. These regions would be activated in patients with first rank symptoms of schizophrenia [51].

An anatomical inversion of the two left and right lower parietal areas might exist in patients with schizophrenia [52]. Also, an increased activity in the lower right parietal aerea has been reported, and could be explained, according to Daprati [45], by the role of the parietal lobe in comparing the executed movement and its sensorial consequences. The difficulties for the patient to attribute the origin of the actions would therefore provoke this overactivation of the right lower parietal lobe. This corresponds to a lack of inhibition of the frontal lobe on the 
lower primary and auditory parietal structures which would induce their overactivation and the disturbances of the self/non-self differentiation. The deficits in visual perception of the patients are not specific to the face. They increase when the cognitive and perceptual load is high, and worsen with chronicity. The first levels of visual recognition are altered by the lack of interaction between magnocellular and parvocellular pathways [53].

\section{- Neurocognitive approach: the Frith model}

Christopher Frith has developed in 1992 a cognitive model of disturbance of consciousness in schizophrenia [54]. This model is based on the concepts of monitoring and self-monitoring. In schizophrenia, there would be an impairment of self-monitoring, or of the system which induces meta- representations. They allow the individual to develop self and other consciousness from representations of his/her own mental content. This is a reflective self-consciousness. This system makes it possible to become aware of the aims and intentions of self or others, and to attribute them accordingly. Patients would not be aware of the consequences of their own actions, and therefore would be in difficulty predicting the consequences of these actions. This may explain the difficulties for some patients to initiate actions. Unaware of the purpose of their actions, patients may engage in inappropriate behavior. Thus, negative symptoms and disorganization could be explained by this disruption of cognitive functioning. Also, positive symptoms may emerge in the patient when monitoring the intent of his/her actions becomes altered. The person attributes over his/her own thoughts and perceives them as external [55].

\section{Conclusion}

It seems essential to understand better schizophrenia in order to be able to detect the symptoms as soon as possible, to set up adapted treatment and improve functional prognosis. The question of self-consciousness, in its affective, cognitive, and bodily aspects, takes on its full meaning in preadolescents and adults whose self-consciousness and other-consciousness is beeing developed [56]. Consideration of the minimal self and its perturbations can have important applications, especially for early diagnosis of schizophrenia. However, one of the limitations we face is that identifying such disorders depends on the verbal expression of patients. The available data must therefore be interpreted with caution, especially because the minimal self is related to non-verbal aspects of consciousness [57]. Therefore, the challenge is to find a way to objectify the minimal self through a nonverbal approach $[58,59]$. The development of the self-image observed in the first months of life could be an interesting indicator of the evolution of this process of consciousness [60]. A new paradigm developed by Moritz Wehrmann using a double mirror [29] makes it possible to explore specifically and objectivally self-other differentiation in the mirror. This paradigm can be used to study the disturbances of self-consiousness in schizophrenia. Finally, a therapeutic use of the mirror could be proposed based on cognitive remediation helping individuals with schizophrenia to improve selfother differentiation.

\section{References}

1. Kircher T, David A. The self in neuroscience and psychiatry. Cambridge University Press (2003).

2. Damasio AR, Larsonneur C, Tiercelin C. Le sentiment même de soi : corps, émotions, conscience. In : Antonio R. Damasio (Ed.) (2002).

3. Kihlstrom JF, Albright JS, Klein SB, et al. Information Processing and the Study of the Self. 145-178 (1988).

4. Jaspers K. Allgemeine psychopathologie. Springer-Verlag (2013).

5. Scharfetter C. General psychopathology: An introduction. CUP Archive (1980).
6. Duval C, Eustache F, Piolino P. Self multidimensionnel, mémoire autobiographique et vieillissement. Psychol. Neuropsychiatr. Vieil 5(3), 179-192 (2007).

7. Parnas J, Handest P. Phenomenology of anomalous self-experience in early schizophrenia. Compr. Psychiatry 44(2), 121 134 (2003).

8. Rochat $P$, Hespos $S$. Differential rooting response by neonates: Evidence for an early sense of self 6(1), 105 (1997).

9. Issel EP. Fetal response to external mechanical stimulation. J. Perinat. Medicine 11(1), 232-242 (1983).

10. Laplanche J, Pontalis JB, Lagache D. Vocabulaire de la psychanalyse. Presses universitaires de France (2002).

11. Piaget J. Les stades du développement intellectuel de l'enfant et de l'adolescent. Le problème des stades en psychologie de l'enfant. Presses Universitaires de Paris, Paris, 33-42 (1956).

12. Winnicott. Jeu et réalité. L'espace potentiel. Gallimard, Paris (1975).

13. Wallon $\mathrm{H}$. Le rôle de l'autre dans la conscience du moi. Enfance 12(3), 277-286 (1959).

14. Moyano O. L'«isthme narcissique», une hypothèse clinique dans les troubles de la conscience de soi chez l'enfant et I'adolescent. Neuropsychiatr. Enfance. Adolesc 50(3), 183-192 (2002). 
15. Gallup GG. Self-awareness and the emergence of mind in primates. Am. J. Primatol 2(3), 237(1982).

16. Suddendorf T, Butler DL. The nature of visual self-recognition. Trends. Cogn. Sci 17(3), 121127 (2013).

17. Zazzo R. Images du corps et conscience de soi. Enfance 1(1), 29-43 (1948).

18. Rochat $P$. Five levels of self-awareness as they unfold early in life. Conscious. Cogn. Déc 12(4), 717-731 (2003)

19. Decety J. Sommerville JA. Shared representations between self and other: a social cognitive neuroscience view. Trends. Cogn. Sci 7(1), 527-533 (2003).

20. Keromnes G, Martin B, Tordjman S. Exploration de la conscience de soi à partir de la reconnaissance de l'image de soi et de l'autre dans le miroir : intérêts dans les troubles schizophréniques et autistiques. Psychiatr. Française 48(1), 57-94 (2017).

21. Amsterdam B. Mirror self-image reactions before age two. Dev. Psychobiol 5(4), 297-305 (1972).

22. Boulanger-Balleyguier $\mathrm{G}$. Les étapes de la reconnaissance de soi devant le miroir. Enfance

23. Kircher T, David A. The self in neuroscience and psychiatry. Cambridge University Press 20(1), 91-116 (1967).

24. Gallup GG, Platek SM, Spaulding KN. The nature of visual self-recognition revisited. Trends. Cogn. Sci 18(2), 57-58 (2014).

25. Rizzolatti G, Sinigaglia C. Neurones miroirs (Les) (2008)

26. Calvo-Merino B, Glaser DE, Grezes J, et al. Action observation and acquired motor skills : an FMRI study with expert dancers. Cereb. Cortex N.Y.N. 1991 15(8), 1243-1249 (2005).

27. Hickok $G$. The myth of mirror neurons: The Real Neuroscience of Communication and Cognition. (2014).

28. Kircher TT, Seiferth NY, Plewnia C, et al. Selfface recognition in schizophrenia. Schizophr. Res 94(1), 264-272 (2008)

29. Thirioux B, Wehrmann M, Langbour N, et al. Identifying oneself with the face of someone else impairs the egocentered visuospatial mechanisms: a new double mirror paradigm to study self-other distinction and interaction. Front. Psychol (2016).

30. Van der Meer L, Costafreda S, Aleman A, et al. Self-reflection and the brain: $A$ theoretical review and meta-analysis of neuroimaging studies with implications for schizophrenia. Neurosci. Biobehav. Rev 34(6), 935-946 (2010).
31. Blanke O, Landis T, Spinelli L, et al. Outof-Body Experience and Autoscopy of Neurological Origin. Brain 127(2), 243 (2004).

32. Ionta S, Heydrich L, Lenggenhager B, et al. Multisensory mechanisms in temporo-parietal cortex support self-location and first-person perspective. Neuron 70(2), 363-374 (2011).

33. Sugiura M, Watanabe J, Maeda Y, et al. Cortical mechanisms of visual self-recognition. Neurolmage 24(1), 143-149 (2005).

34. Keenan JP, McCutcheon B, Freund S, et al. Left hand advantage in a self-face recognition task. Neuropsychologia 37(12), 1421 (1999).

35. Hu C, Di X, Eickhoff SB, et al. Review: distinct and common aspects of physical and psychological self-representation in the brain: A meta-analysis of self-bias in facial and self referential judgements. Neurosci. Biobehav. Rev 61(1), 197 (2016).

36. Lenggenhager B, Tadi T, Metzinger T, et al. Video Ergo Sum: Manipulating Bodily SelfConsciousness. Science 317(5841), 1096-1099 (2007).

37. Melchior-Bonnet S. Histoire du miroir. Imago (1994).

38. Minkowski E. La schizophrénie. Editions Payot (1927).

39. Binswanger. Introduction à l'analyse existentielle (1971)

40. Sass LA, Parnas J. Schizophrenia, consciousness, and the self. Schizophr. Bull 29(3), 427-444 (2003)

41. B. Martin, A. Giersch, M. Cermolacce, et al. Self minimal et schizophrénie. Psychiatrie (2016).

42. Harrington A, Oepen G, Spitzer M. Disordered recognition and perception of human faces in acute schizophrenia and experimental psychosis. Compr. Psychiatry 30(5), 376-384 (1989).

43. Laroi F, D’Argembeau A, Brédart S, et al. Face recognition failures in schizotypy. Cognit. Neuropsychiatry 12(6), 554-571 (2007).

44. Bortolon C, Capdevielle D, Salesse RN, et al. Further insight into self-face recognition in schizophrenia patients: Why ambiguity matters. J. Behav. Ther. Exp. Psychiatry 50, 215222 (2016).

45. Daprati E, Franck N, Georgieff N, et al. Looking for the agent: an investigation into consciousness of action and selfconsciousness in schizophrenic patients. Cognition 65(1), 71-86 (1997)

46. Farrer C, Franck N. Sens du corps dans la schizophrénie. L'Encéphale 35(1), 43-51 (2009).

47. Klaver M, Dijkerman HC. Bodily experience in Schizophrenia: factors underlying a disturbed sense of body ownership. Front. Hum. Neurosci 10, 305 (2017).

48. Garbarini F, Mastropasqua A, Sigaudo M, et al. Abnormal Sense of Agency in Patients with Schizophrenia: Evidence from Bimanual Coupling Paradigm. Front. Behav. Neurosci. 9, 10-43 (2016).

49. Robinson JD, Wagner N-F, Northoff G. Is the Sense of Agency in Schizophrenia Influenced by Resting-State Variation in Self-Referential Regions of the Brain? Schizophrenia. Bulletin. 42(2), 270-276 (2016).

50. Jeannerod M. Les troubles de la reconnaissance de soi : une approche neuropsychologique des symptômes positifs de la schizophrénie. Médecine/sciences 19(5), 621-624 (2003).

51. Spence SA, Brooks DJ, Hirsch SR, et al. A PET study of voluntary movement in schizophrenic patients experiencing passivity phenomena (delusions of alien control). Brain 120(11), 1997-2011 (1997)

52. Niznikiewicz $M$, Donnino R, Niznikiewicz $M$, et al. Abnormal angular gyrus asymmetry in schizophrenia. Am. J. Psychiatry 157(3), 428 (2000)

53. Bortolon C, Capdevielle D, Altman R, et al. Mirror self-face perception in individuals with schizophrenia: Feelings of strangeness associated with one's own image. Psychiatry. Res 253(1), 205-210 (2017).

54. Frith CD. Consciousness, information processing and schizophrenia. Br. J. Psychiatry 134(3), 225-235 (1979).

55. Roy M, Roy M-A, Grondin S. Les perturbations de la conscience dans la schizophrénie : évaluation du modèle de C.D. Frith. L.'Encéphale (2008).

56. Martin B, Wittmann M, Franck N, et al. Temporal structure of consciousness and minimal self in schizophrenia. Front. Psychol (2014).

57. Korkmaz B. Theory of mind and neurodevelopmental disorders of childhood. Pediatr. Res 69(5 Pt 2), 101R-108R (2011).

58. Mishara A. Missing links in phenomenologica clinical neuroscience: Why we still are not there yet. 20(1), 559 (2011).

59. Mishara AL, Lysaker PH, Schwartz MA. Selfdisturbances in schizophrenia: history, phenomenology, and relevant findings from research on metacognition. Schizophr. Bull 40(1), 5-12 (2014)

60. Tordjman S, Maillhes AS. Les troubles du développement de l'image du corps dans la petite enfance : une dimension commune partagée par la schizophrénie et l'autisme? Schizophrénies. Précoces 57(1), 6-13 (2009). 